\title{
Neisseria gonorrhoeae, Beta-lactamase Negative Measurement
}

National Cancer Institute

\section{Source}

National Cancer Institute. Neisseria gonorrhoeae, Beta-lactamase Negative

Measurement. NCl Thesaurus. Code C161399.

The determination of the amount of beta-lactamase negative Neisseria gonorrhoeae present in a sample. 